\title{
Flowering and Corm Yield of Brodiaea in Response to Temperature, Photoperiod, Corm Size, and Planting Depth
}

\author{
Susan S. Han', Abraham H. Halevy², Roy M. Sachs, and Michael S. Reid \\ Department of Environmental Horticulture, University of California, Davis, CA 95616 \\ Additional index words. Triteleia laxa, Brodiaea laxa
}

\begin{abstract}
Flowering of brodiaea (Triteleia laxa syn. Brodiaea laxa 'Queen Fabiola') did not have an obligate requirement for manipulation of temperature or photoperiod. Vernalization of corms reduced the greenhouse forcing phase but did not alter the number of flowers per inflorescence or scape length. Long photoperiods hastened flowering but decreased flower quality and flowering percentage. Scape length, which was not affected by photoperiod or mother corm size, was increased when plants were grown at night temperatures $<10 \mathrm{C}$. Diameter of the apical meristem in the dormant corm, flowering percentage, and flower quality were not affected by a $\mathbf{1 0 - f o l d}$ increase in corm size above a critical weight $(0.6 \mathrm{~g})$. In contrast, the weight and number of daughter corms were closely correlated with mother corm size. The optimum planting depth for brodiaea corms was $10 \mathrm{~cm}$ below the soil surface.
\end{abstract}

Brodiaea has gained popularity in recent years as a cut-flower crop, and other members of the brodiaea complex show considerable commercial potential (Halevy and Kofranek, 1989). The success of many geophytes in commerce relies on the ability to manipulate their flowering to ensure an extended flowering period. In commerce, flowering of these plants is manipulated mainly by exposing the storage organs (bulbs, corms, etc. ) to specific temperature regimes (Rees, 1985). Photoperiod, which is the major environmental factor controlling flowering of herbaceous species, is of minor importance in the flowering of commercial neophytes.

The size of the perennating organ also determines whether a geophyte will flower. Even under favorable conditions, bulbs below a critical size fail to flower (Rees, 1985). Above this critical size, flower quality (number of flowering shoots, number of florets per inflorescence, and stem length) often improves as size of the mother bulb increases.

The effects of the forcing environment on flowering of brodiaea were studied by Fortanier (1969). He used corms that had been stored at $23 \mathrm{C}$ and held for 4 to 7 weeks at $5 \mathrm{C}$ before planting. High temperature during forcing accelerated flowering but decreased the percentage of flowering plants, the number of flowers per inflorescence, and the length of the scape. The whole growth cycle was accelerated by extended daylengths. The percentage of plants that flowered and the number of flowers per inflorescence were reduced in long days. Photoperiodic treatment had no effect on the final length of the scape. Fortanier stored brodiaea corms under conditions established for other cormous plants, but we found no reports on the effects of preforming temperatures on flower initiation and forcing behavior of brodiaea nor on the effects of corm size and planting depth on growth and flowering. The objectives of our study were to study flowering and corm yield in brodiaea as a function of

Received for publication 29 Dec. 1988. This study was partially supported by BARD research Proiect \#I-795-84. The cost of publishing this paper was defrayed in part by the payment of page charges. Under postal regulations, this paper therefore must be hereby marked advertisement solely to indicate this fact.

'Present address: Department of Plant and Soil Sciences, French Hall, University of Massachusetts, Amherst, MA 01003.

${ }^{2}$ Permanent address: Faculty of Agriculture, The Hebrew University of Jerusalem, Rehovot, 76-100, Israel. corm storage temperature, photoperiod, mother corm size, and planting depth.

\section{Materials and Methods}

Temperature. In an initial experiment in Dec. 1985, corms obtained from a commercial producer in northern California (average weight $1 \mathrm{~g}$ ) were planted individually in PVC containers containing U.C. mix ( 1 sand $: 1$ redwood bark :1 peat, by volume) or held dry at 0,3 , or $7 \mathrm{C}$ for 4,8 , or 12 weeks before planting. Control corms were held dry at $20 \mathrm{C}$ for the same periods. The planted corms were grown in a $24 / 18 \mathrm{C}$ (day/ night) greenhouse and the flowering dates and percentage of plants flowering were recorded. Ten replications were used for each treatment.

Temperature and photoperiod. In a subsequent experiment in Nov. 1986, plants were forced under controlled daylengths. Corms (average weight $1.3 \mathrm{~g}$ ) were planted as described above. The medium was watered and the plants were divided into two lots, one held at 20C in darkness and the other at 5C in darkness for 5 or 12 weeks. Following the pretreatment, plants were placed in a greenhouse at 24/18C (day/night) and given two photoperiod treatments, either a short-day (SD, $8 \mathrm{hr}$ natural light) or a long-day (LD, $8 \mathrm{hr}$ natural light plus $16 \mathrm{hr}$ of $5 \mu \mathrm{mol} \cdot \mathrm{s}^{-1} \cdot \mathrm{m}^{-2}$ incandescent light from 4:30 PM to 8:30 AM) throughout the growing period. Ten replications were used for each treatment.

Mother corm size. Vegetative apical meristems from dormant corms of various sizes were dissected and then fixed with $2 \%$ glutaraldehyde in $0.1 \mathrm{M}$ phosphate buffer $(\mathrm{pH} 7.0)$, dehydrated by passing through an ethanol series ( $0 \%$ to $100 \%)$, and critical point-dried in $\mathrm{CO}_{2}$. They were examined and photographed using an ISI DS130 scanning electron microscope (SEM). The diameter of the apical dome was measured at the level of insertion of the youngest leaf primordium. There were three replications per treatment.

In Nov. 1986 and 1987, corms were classified by weight into six size classes, then planted individually in PVC containers containing loamy sand. They were grown outdoors in Davis, Calif. The inflorescences were harvested and weighed when the first floret reached anthesis. Propagule fresh weights and the number of cormels produced were determined when the leaves had senesced in July of the following year. There were 20 replications per treatment. 
Table 1. Effect of vernalization at $5 \mathrm{C}$ and photoperiod on the flowering of Triteleia laxa ('Queen Fabiola'). Data are means of 10 plants.

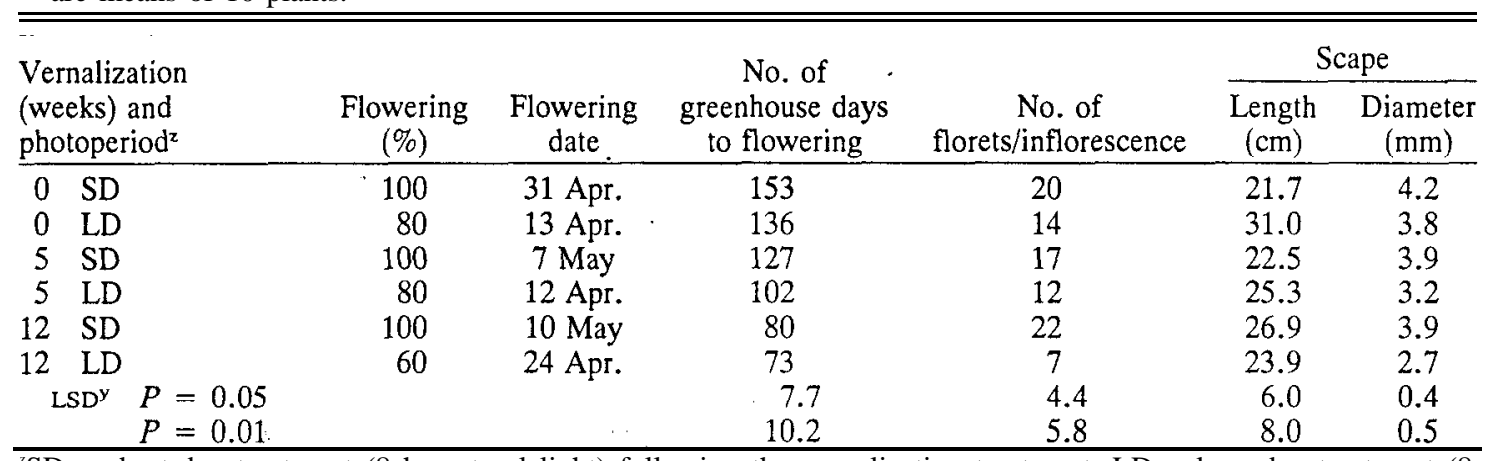

${ }^{z} \mathrm{SD}=$ short-day treatment $(8 \mathrm{hr}$ natural light $)$ following the vernalization treatment; LD = long-day treatment $(8$ hr natural light plus $16 \mathrm{hr}$ of $5 \mu \mathrm{mol} \cdot \mathrm{s}^{-1} \cdot \mathrm{m}^{-2}$ incandescent light) following the vernalization treatment.

${ }^{y}$ Mean separation within columns by Fisher's least significant difference test.

Night temperature. Corms were planted in U.C. mix and grown under $8 \mathrm{hr}$ natural days in a $24 \mathrm{C}$ greenhouse and moved to dark chambers at $5,10,21$, or $25 \mathrm{C}$ for $16 \mathrm{hr}$ each night throughout the growing period. Scape length of each inflorescence was measured at anthesis. There were 20 replications per treatment.

Planting depth. In Dec. 1985, corms (average weight $1.1 \mathrm{~g}$ ) were planted individually in PVC containers containing loamy sand on the surface, $5,10,15$, or $20 \mathrm{~cm}$ below the surface and grown outdoors in Davis. The percentage of plants that flowered (percentage of flowering), number of flowers per inflorescence, and daughter corm and cormel fresh weights were collected. There were 15 replications per treatment.

\section{Results}

Cold storage of corms and photoperiod. A preliminary experiment indicated that there was little or no effect of temperature during storage on the forcing period for brodiaea corms. Corms held dry for 4 or 8 weeks at 0,3 , or $7 \mathrm{C}$ before planting flowered at the same time as "those held dry at 20C, when grown under short natural daylengths (data not shown). In a subsequent experiment, we examined the effect of wet storage at $5 \mathrm{C}$ and growth under controlled daylengths (Table 1). Vernalization had no significant effect on percentage flowering and number of flowers per in florescence in plants grown in short days; but corms stored 12 weeks and grown under long photoperiods produced fewer and significantly poorer quality spikes (thinner scapes and fewer flowers per inflorescence).

Although the actual flowering date differed little among treatments, low-temperature storage significantly reduced the forcing period (Table 1). Forcing under long days advanced flowering by 1 to 3 weeks (Table 1). Neither temperature nor photoperiod affected scape length.

Size of mother corm. Although nearly all corms sprouted after planting, the percentage of flowering decreased rapidly below a corm weight of $\approx 0.6 \mathrm{~g}$ (Fig. 1, top). Only $50 \%$ of plants from corms weighing $0.25 \mathrm{~g}$ flowered, and corms weighing $\leq 0.1 \mathrm{~g}$ did not flower. The size of the apical dome in dormant corms increased markedly as corm size increased from 0.1 to $0.6 \mathrm{~g}$ (Fig. 1, bottom). Thereafter, meristem diameter did not change over an 8-fold increase in corm size. Scape length was not significantly affected by corm size (Fig. 2, top), and the number of flowers per inflorescence was reduced significantly only in very small corms $(\leq 0.6 \mathrm{~g})$. As the mother corm size increased, the number and fresh weight of the daughter corms increased significantly (Fig. 2, bottom). The combined weight of daughter corms and cormels was about five times that of the mother corm.

Depth of planting. Flowering percentage declined with increased planting depth (Fig. 3, top), but the number of flowers per inflorescence and the fresh weight of daughter corms and cormels was maximal in corms planted $10 \mathrm{~cm}$ from the nose to the soil surface (Fig. 3, bottom).

Night temperature. Low night temperatures promoted scape elongation. Scapes of plants grown at 5 or 10C night temperature were more than twice as long as those of plants grown at higher night temperatures (Fig. 4).

\section{Discussion}

Brodiaeas did not have an obligatory requirement for temperature or photoperiod for flowering. However, environmental factors modulated flower quality and the rate of flower initiation and development. We, as Fortanier (1969), found that long photoperiods hastened flowering but decreased flower quality (number of flowers per inflorescence and scape diameter) and flowering percentage. Our data (Table 1) indicate that flower quality (number of flowers per inflorescence) was not affected by the low-temperature pretreatment used by Fortanier (1969). In our experiments, flowering date was not significantly affected by vernalization treatments, although they did markedly reduce the time required for forcing in the greenhouse (Table 1). We used corms that had been stored at 20C dark condition for several months after lifting, and we would therefore not have seen any effect of low temperature on corm dormancy. Experiments with other species from the Brodiaea complex have suggested that freshly lifted corms are dormant; in such corms, vernalization may hasten flowering by advancing the breaking of dormancy (Halevy and Kofranek, 1989).

Scape length, a very important quality characteristic in brodiaea flowers, was little affected by corm size, cold pretreatment, or photoperiod during forcing (Table 1, Fig. 2, top). However, scape length increased $250 \%$ in plants forced under low (5 to 10C) night temperatures (Fig. 4). This dramatic increase was not accompanied by any decrease in flower quality or increase in forcing time (data not shown). This relationship suggests that low night temperatures should be used in commercial production of brodiaeas.

In brodiaeas, the daughter corm is formed by enlargement of the basal portion of the stem; cormels are formed from axillary buds on the mother corm. Planting depth, which affects the 

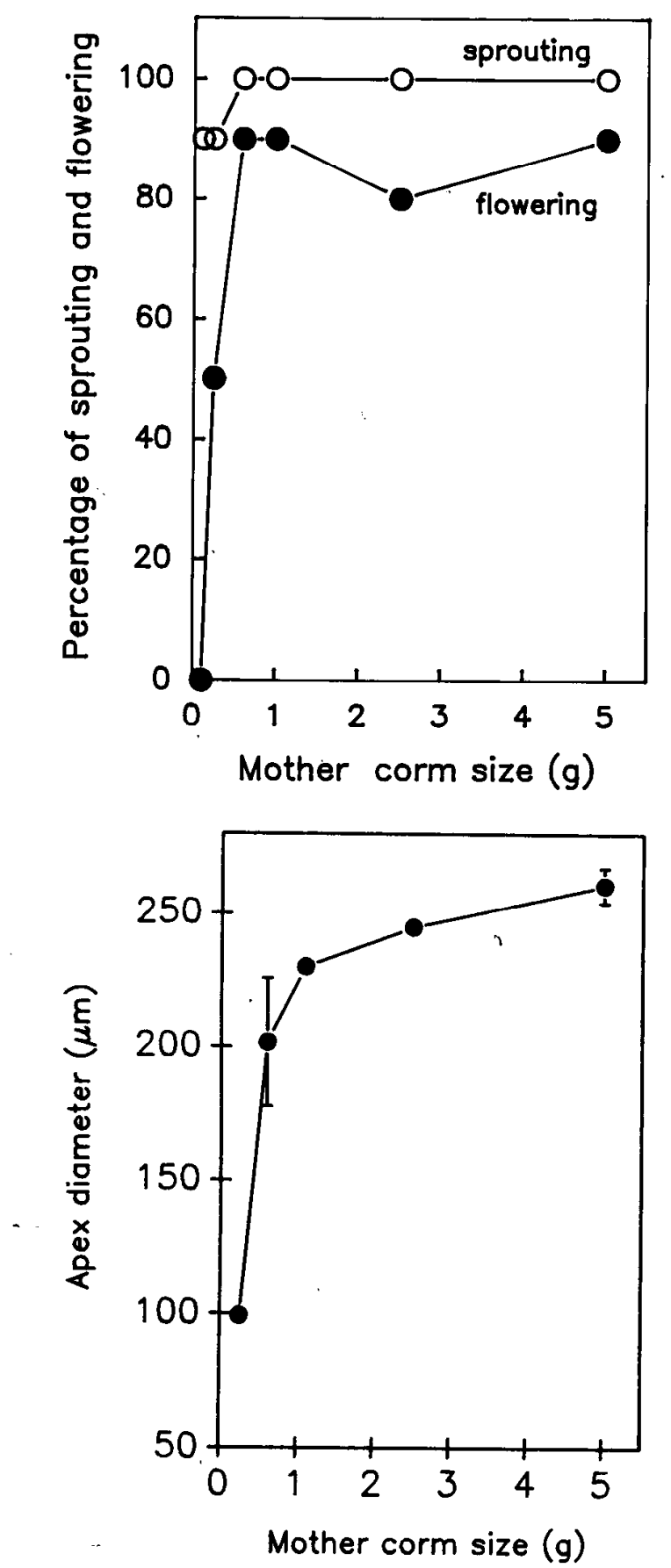

Fig. 1. Effects of brodiaea mother corm size on (top) percentage of sprouting and flowering and (bottom) apical dome size. Vertical bars represent SE; bars smaller than the symbols are not shown.

formation of Oxalis and Gladiolus corms (Iziro and Hori, 1983), also influenced flower quality and the production of daughter corms and cormels of brodiaea. Shallow planting resulted in death of some daughter corms. Although flowering percentage was maximal when corms were not buried, the improved flower quality and daughter corm and cormel production in corms planted at a depth of $10 \mathrm{~cm}$ indicate that this depth is optimal for commercial production of brodiaeas.

The number of cormels of brodiaea increased with increasing size of the mother corm (Fig. 2, bottom), presumably because larger mother corms have more axillary buds.

In most geophytes, flowering percentage and flower quality
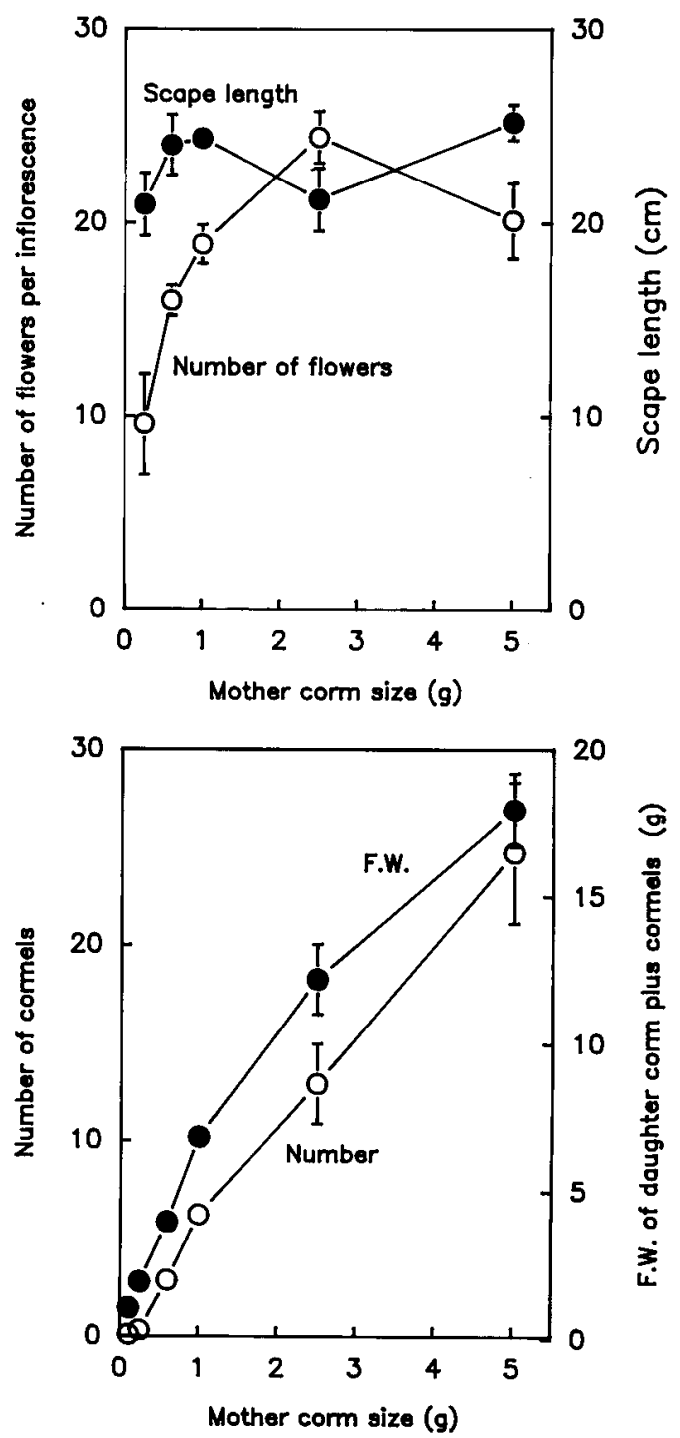

Fig. 2. Effects of brodiaea mother corm size on (top) number of flowers per inflorescence and scape length and (bottom) combined fresh weight (FW) and number of daughter corm and cormels. Vertical bars represent SE; bars smaller than the symbols are not shown.

are correlated with the size of the mother propagule. In contrast, the percentage flowering and flower quality in brodiaea was independent of mother corm size for corms $>0.6 \mathrm{~g}$ (Figs. 1, top, and 2, top). There is disagreement as to whether it is the increase in storage carbohydrate or the enlargement of the apical meristem size with increased mother bulb size that determines the quality of the flowers. In Dutch iris and lily, bulb size is correlated with the apex diameter (Doss and Christian, 1979; Kohl, 1967); it has been suggested that there is a critical meristem size below which flower induction will not take place in these species. According to this hypothesis, flower quality improves as the meristem increases in size because of the greater space available on the dome for the formation of floral primordia (De Hertogh et al., 1976; Rees, 1985). This hypothesis is consistent with the data of Kohl (1967), who demonstrated that apex size falls during vernalization of lilies, a treatment accompanied by a reduction in flower number. Wang et al. (1970) argued that cessation of initiatory activity rather than reduced apical dome size might be the cause of the reduced flower numbers accompanying longer vernalization. In brodiaea, the apical 

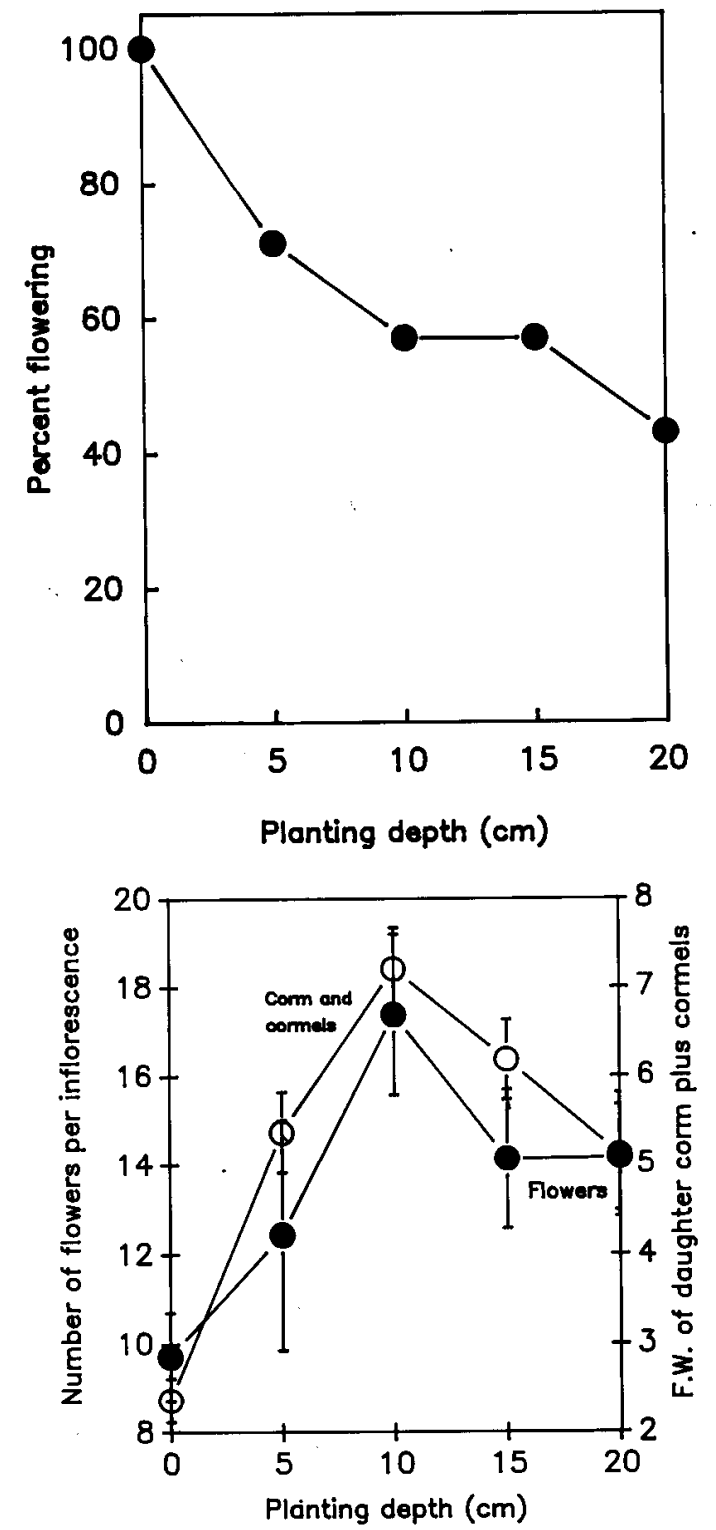

Fig. 3. Effects of planting depth on (top) percentage of flowering and (bottom) number of flowers per inflorescence and combined fresh weight of brodiaea daughter corm and cormels. Vertical lines represent SE.

meristem size in dormant corms increased rapidly as the mother corm size increased from 0.2 to $0.6 \mathrm{~g}$. Thereafter, there was no significant increase over an 8 -fold increase in corm size ranging from 0.6 to $5 \mathrm{~g}$ (Fig. 1, bottom). These changes were almost exactly mirrored in the changes in percentage flowering and flower quality with increasing corm size. These data strongly support the hypothesis that flowering and flower number are determined by size of the apical dome.

Ethylene pretreatment of small brodiaea corms, which markedly enhances their flowering potential (Han et al., 1990), also doubles the growth rate of their meristems. This observation further supports the hypothesis that flowering is closely related to the size of the meristematic dome.

The data presented here suggest that for optimum commercial

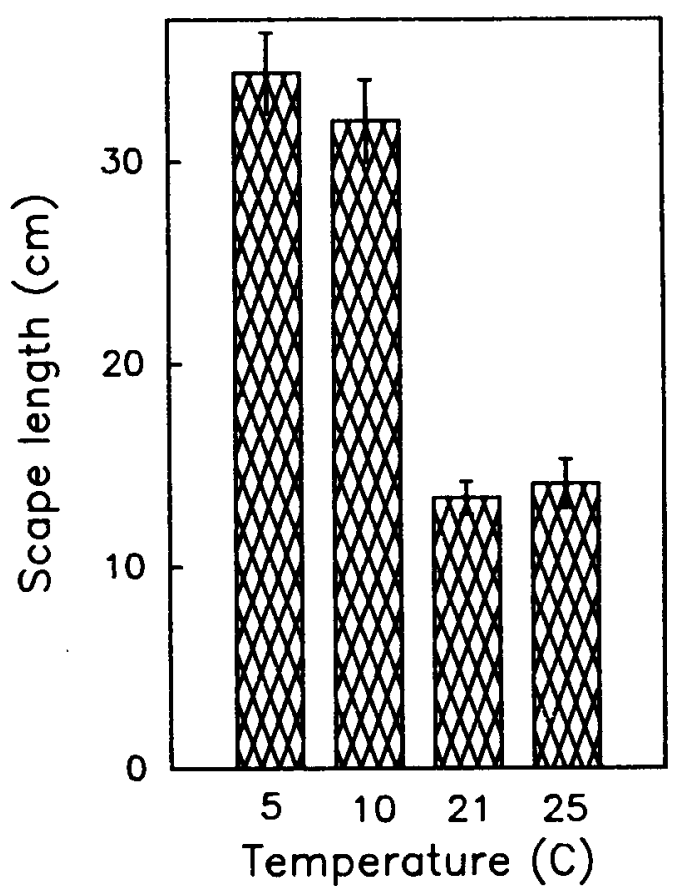

Fig. 4. Effects of night temperature on scape length of brodiaea. Vertical lines represent SE.

production of brodiaeas, corms (minimum size $0.6 \mathrm{~g}$ ) should be planted $10 \mathrm{~cm}$ below the soil surface in a well-drained, sterilized planting medium. Plants should be grown at low night temperatures (5 to 10C) during forcing to promote scape elongation. Although long photoperiods advance flowering, they reduce flowering percentage and the quality of the inflorescence.

\section{Literature Cited}

De Hertogh, A. A., H.P. Rasmussen, and N. Blakely. 1976. Morphological changes and factors influencing shoot apex development of Lilium longiflorum Thunb. during forcing. J. Amer. Sot. Hort. Sci. 101(4):463-471.

Doss, R.P. and J.K. Christian. 1979. Relationships between bulb size, apex size, and flowering in bulbous iris cv. Ideal. Physiol. Plant. 45:215-218.

Fortanier, E.J. 1969. The influence of temperature, light energy and photoperiod on flowering of Brodiaea laxa Wats. Netherlands J. Agr. Sci. 17:176-182.

Halevy, A.H. and A.M. Kofranek. 1989. Introduction of plants from the brodiaea complex as new cut flowers. Final report BARD research project no. I-795-84. Bet Dagan, Israel.

Han, S. S., A.H. Halevy, R.M. Sachs, and M.S. Reid. 1990. Enhancement of growth and flowering of Triteleia Laxa by ethylene. J. Amer. Soc. Hort. Sci.115(3):482-486.

Iziro, Y. and Y. Hori. 1983. Effect of planting depth on the growth of contractile roots and daughter corm of bulbs in gladiolus and Oxalis bowaieana Lodd. J. Jpn. Soc. Hort. Sci. 52:51-55.

Kohl, H.C. 1967. Correlation between rate of initiation and apex diameter of Lilium longiflorum cultivar 'Ace'. HortScience 2:15-16.

Rees, A.R. 1985. Ornamental bulbous plants, p. 259-307. In: A.H. Halevy (cd.). Handbook of flowering. vol. I. CRC Press, Boca Raton, Fla.

Wang, S. Y., A.N. Roberts, and L.T. Blaney. 1970. Relationship between length of vernalization, stem apex size, and initiatory activity in Lilium longiflorum cv. Ace. HortScience 5:113-114. 